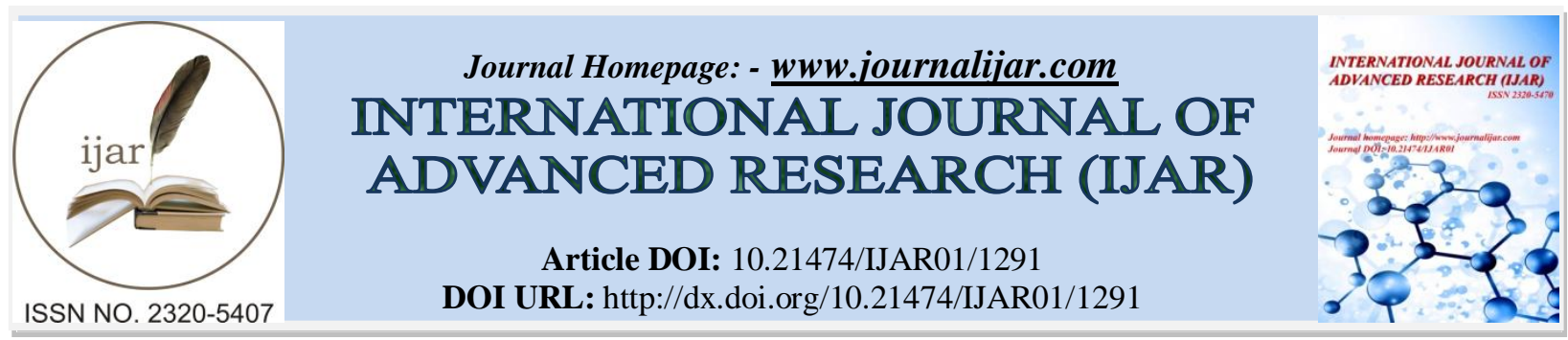

RESEARCH ARTICLE

\title{
RADON GAS EXPOSURE LUNG CANCER AMONG NON SMOKER SUSING IMAGE MINING.
}

\section{Dr.M.Mohamed Suphudeen, B.Mohamed Faize Basha.}

1. Associate professor,dept.of .computer science,jamal mohamed college, trichy.

2. Asst.prof.of. Computer science, jamal mohamed college, trichy,tamilnadu.

\section{Manuscript Info}

Manuscript History

Received: 12 June 2016

Final Accepted: 19 July 2016

Published: August 2016

Key words:-

image mining, cancer, cell, tumours, Radon ,non-smokers.

\section{Abstract}

Image Mining is an extended branch of data mining that is concerned with the process of knowledge discovery concerning images. Image Mining deals with the extraction of image patterns from a large collection of images. Image mining is primarily used to the requirements of finding the various applications in diverse fields such as retail, financial, communication, marketing organizations and medicine, For Improve the detection of disease in the medical field image mining techniques is widely used today. This paper describes the process of lung cancer detection and curing possibilities among non smokers. It may recover possible to the early stage. In general lung cancer is the uncontrolled growth of abnormal cells that start off in one or both lungs. The cancer cells can break and damage the tissues and also organs near the tumours of the body. It spread from one place to another.

Especially we deals with Radon exposure(1) and how affect nonsmokers. Using image quality and accuracy is the main factor for earlier disease detection and treatment stages including non-smokers also. Image mining has two different approaches one is extracted and collected in pattern.

Copy Right, IJAR, 2016,. All rights reserved.

\section{Introduction:-}

Lung cancer is a cancer that starts in the lungs. To understand lung cancer, it helps to know about the normal structure and function of the lungs. Detecting and classified of the cancer for different medical images uses the high accuracy because they deal with human life. Today's computer professional can handle this situation very well but in some case false negative cases must be detected or classified at a very low rate. So we suggest that the improvement of the detection for cancer, especially lungs

( LCDD) is necessary affecting Radon gas among non-smokers.

Radon is a colorless chemically-un reactive inert gas. The atomic radius is 1.34 angstroms and it is the heaviest known gas--radon is nine times denser than air. Because it is a single atom gas (unlike oxygen, $\mathrm{O} 2$, which is comprised of two atoms) it easily penetrates many common materials like paper, leather, low density plastic (like plastic bags, etc.) most paints, and building materials like gypsum board (sheetrock), concrete block, mortar, sheathing paper (tarpaper), wood paneling, and most insulations. 
Radon(2) is also fairly soluble in water and organic solvents. Although reaction with other compounds is comparatively rare, it is not completely inert and forms stable molecules with highly electronegative materials. Radon is considered a noble gas that occurs in several isotopic forms. Only two are found in significant concentrations in the human environment: radon-222, and radon-220. Radon-222 is a member of the radioactive decay chain of uranium-238. Radon-220 is formed in the decay chain of thorium-232. Radon-222 decays in a sequence of radio nuclides called radon decay products, radon daughters, or radon progeny. It is radon-222 that most readily occurs in the environment. Atmospheric releases of radon-222 results in the formation of decay products that are radioisotopes of heavy metals (polonium, lead, bismuth) and rapidly attach to other airborne materials such as dust and other materials facilitating inhalation.

Image mining(3) is currently a growing yet active research focus in computer science. The fundamental challenge in image mining is to reveal out how low-level pixel

representation enclosed in a raw image or image sequence can be processed to recognizehigh-level image objects and relationships.

Image mining is the process of searching and discovering valuable information and knowledge in large volumes of data. Image mining draws basic principles from concepts in databases, machine learning, statistics, pattern recognition and 'soft' computing. Using data mining techniques enables a more efficient use of data banks of earth observation data.

It is thus becoming an emerging research field in geosciences because of the increasing amount of data which lead to new promising applications.

\section{Exposure:-}

The primary routes of potential human exposure to radon are inhalation and ingestion. Radon in the ground, groundwater, or building materials enters working and living spaces and disintegrates into its decay products. Although high concentrations of radon in groundwater may contribute to radon exposure through ingestion, the inhalation of radon released from water is usually more important.

A method of locating lung cancer victims within neighborhoods based on the likelihood that the majority of the structures will have radon measurement levels within a similar range.

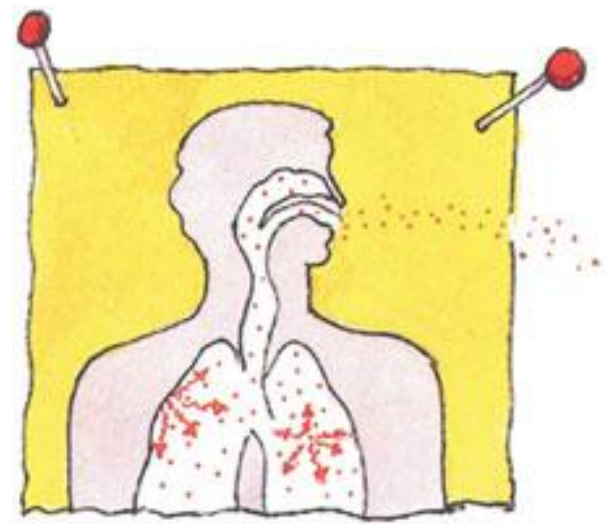

Start and spread of lung cancer:-

The above fig. shows that Radon effect for health.

Lung cancers can start in the cells lining the bronchi and parts of the lung such as thebronchioles or alveoli.Lung cancers are thought to start as areas of pre-cancerous changes in the lung. The firstchanges in the genes (DNA) inside the lung cells may cause the cells to grow faster. These cells may look a bit abnormal if seen under a microscope, but at this pointthey donot form a mass or tumor.

\section{Signs and symptoms of lung cancer:-}

Most lung cancers do not cause any symptoms until they have spread too far to be cured,but symptoms do occur in some people with early lung cancer. If you go to your doctorwhen you first notice symptoms, your cancer might be diagnosed at an earlier stage, when treatment is more likely to be effective. 
The most common symptoms of lungcancer are:-

A cough that does not go away or gets worse

Chest pain that is often worse with deep breathing, coughing, or laughing

Hoarseness

Weight loss and loss ofappetite

Coughing up blood or rustcolored sputum (spit or phlegm)

Shortness of breath

Feeling tired or weak

Infections such as bronchitis and pneumonia that don't go away or keep coming back

New onset of wheezing

For example, total deaths worldwide caused by cancer each year;

Lung cancer---1,370,000 deaths

Stomach cancer----736,000 deaths

Liver cancer----695,000 deaths

Colorectal cancer----608,000 deaths

Breast cancer----458,000 deaths

Cervical cancer----275,000 deaths.

Most radon-related health studies have been criticized because of their very limited residential measurement data.

Lung Cancer Happens in Non-Smokers:-

Smoking is the leading cause of lung cancer, but at the current time, the majority of people who develop lung

cancer do not currently smoke. Overall, over 50 percent of lung cancers occur in former smokers. In addition, 20 percent of women and 1 in 12 men who develop lung cancer have not smoked a single cigarette.

In recent years, the incidence of lung cancer in non-smokers has been increasing. This is not just a proportion, meaning that it isn't just because fewer people are smoking or getting smoking-related lung (4)cancer. Nobody knows exactly why this is happening, but it is not because of secondhand smoke exposure as some people might expect.

Radon, an inert gas released during the decay of uranium-238, is ubiquitous in indoor and outdoor air and contaminates many underground mines. Extensive epidemiologic evidence from studies of underground miners and complementary animal data have documented that radon causes lung cancer in smokers and nonsmokers. Radon must also be considered a potentially important cause of lung cancer for the general population, which is exposed through contamination of indoor air by radon from soil, water, and building materials.

\section{Sources of Radon}

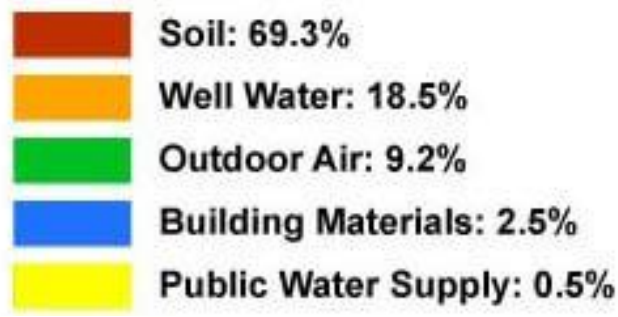

The leading cause of lung cancer in non-smokers is exposure to radon gas, according to the US Environmental Protection Agency (EPA). It accounts for about 21,000 deaths from lung cancer each year. Radon occurs naturally outdoors in harmless amounts, but sometimes becomes concentrated in homes built on soil with natural uranium deposits. Studies have found that the risk of lung cancer is higher in those who have lived for many years in a radon-contaminated house. Because radon gas can't be seen or smelled, the only way to know whether it's a problem in your home is to test for it. 


\section{Conclusion:-}

According to the various cancer diseases affect or caused by the people, most of the deaths are possibilities of lung cancer only. In feature, the high ratio of smokers among lung cancer patients indicates the importance of smoking in lung cancer not only for smokers including lot of non-smokers can be affect in the cancer diseases. we may try to any other method or any technique using with the help of image mining, some avoid may occur possible.

\section{References:-}

1. Field, R. William. "The Iowa Radon Lung Cancer Study". Department of Occupational and Environmental Health, University of Iowa. Retrieved February 22, 2008.

2. American Cancer Society Cancer Facts \& Figures 2010. Atlanta, GA: Available at:http://www.cancer.org/Research/CancerFactsFigures/CancerFactsFigures. Accessed September 6, 2010

3. Aswini Kumar Mohanty et al., (2010) have applied image mining in the domain suchas breast mammograms to classify and detect the cancerous tissue. A hybrid approach offeature selection using fast branch and bound algorithm

4. International Journal of Advanced Research in Computer and Communication Engineering Vol. 3, Issue 7, July 2014 Copyright to IJARCCE www.ijarcce.com 7622 Mining Lung Cancer Data for Smokers and NonSmokers by Using Data Mining Techniques Thangaraju P1, Barkavi G2, Karthikeyn. 